\title{
EXPERIMENTAL AND THEORETICAL DATA ON RADIOCARBON VARIATION IN THE EARTH'S ATMOSPHERE IN THE PAST
}

\author{
V A DERGACHEV
}

A F Ioffe Physical Technical Institute of the Academy of Sciences of the USSR, Leningrad 194021, USSR

ABSTRACT. Some questions in the siudy of cosmic ray intensity (solar magnetic field, irregular solar activity, ${ }^{14} \mathrm{CO}_{2}$ and ${ }^{14} \mathrm{CO}$ in radiocarbon models, etc) on the basis of ${ }^{14} \mathrm{C}$ concentration in the earth's atmosphere are considered.

\section{INTRODUCTION}

Using new highly-sensitive nuclear methods of low-level activity isotope investigations and the theoretical study of production and propagation mechanisms of these isotopes on different cosmic scales, we should be able to unclerstand many current natural processes as well as those that occurred in the past.

Within the framework of the problem of astrophysical phenomena and radiocarbon, principal attention is paid to the cosmic ray intensity changes in the past and to the interpretation of the phenomena associated with them. This information is currently being obtained by means of cosmogenic isotopes in different parts of the environment. Some aspects of this problem have been considered by Dergachev and Kocharov (1979).

Let us dwell briefly on some questions in the study of cosmic ray intensity on the basis of ${ }^{14} \mathrm{C}$ content in the earth's atmosphere obtained from dendrochronologically dated wood samples.

\section{Dendrochronologic samples}

Research in dendrochronology in the USSR has been in progress for the past 10 years due to the development of All-Union problem of cosmic rays intensity variations study by means of cosmogenic isotopes in various dated samples. The dendrochronologic and dendroclimatologic laboratory operates in Kaunas within the framework of this problem. Dendrochronology brought fourth dimensional time to some natural sciences and it is important to continue this time as far into the past as possible. The bristlecone pine tree-ring chronology, as established by Fergusson (1972) at the University of Arizona, encompasses 8253 years. European tree-ring sequences cover shorter time scales.

Pine, fir, and oak trees are the most widespread and investigated species of wood in the USSR. Most annual ${ }^{14} \mathrm{C}$ measurements have been made on dendrochronologically dated pine from Karelia with 525 rings. A method of cross-dating tree-ring series of living trees from the existing forest with that extracted from peat strata, water basins, etc, is projected for a long-term dendrochronologic chart.

The chronology of Lithuanian peat strata pine covers a period of 20 centuries (Bitvinskas and others, 1978). There is a sufficient amount of these pine wood samples to study the ${ }^{14} \mathrm{C}$ annual content.

Even more opportunities for studying annual ${ }^{14} \mathrm{C}$ variations are provided by Smorgon oak samples from gravel beds of the Villa River 
near the town of Smorgon. Presumably, this dendrochronologic chart will go back approximately 6000 years from the present (Bitvinskas and others, 1978). The chronology of the Novgorod chart ranges from AD 884 to 1596 (Kolchin, 1972). This collection contains more than 7800 samples of full sections of logs and blocks of ancient wood. Also, the northern regions of taiga forest, both in the European and Asian parts of the USSR, Kamchatka, etc, are good prospects for the development of dendrochronology and radiocarbon investigations.

The study of cyclicity in natural processes is interesting when applied statistically to long-term predictions. Such regularities may be manifested in tree rings. At present, principal regularities in annual pine growth and their relation to solar activity for the dendroclimatologic profiles from Murmansk to Karpathia are being investigated. The study of the characteristics of time series has been made. The following indicates the annual growth of wood in the north to south direction for the series spectra in the region of middle frequency components corresponding to approximately 10 to 20 years: the maximum power spectrum comes into the period 22 years, the second component period being $T \approx 10.4$ years for the northern regions (Karelia). For the southern regions (Byelorussia, Karpathia), cyclicities are observed in frequencies corresponding to $T \approx$ 11-year periods. For middle regions (Novgorod), the spectrum is unstable and irregular; only components equal to $T \approx 14$ to 18 years may be different from the background.

Using the modified Wolf's number series W (solar activity is characterized by the sign, the positive sign is ascribed to the odd cycle), $i e$, for the series with the 22-year component, the correlation between Wolf's numbers and growth indices is investigated. The correlation proved positive for the northern woods disturbed for the middle regions, negative for the southern regions.

Thus, discovered regularities have distinct latitude dependence that is also manifested in relationships between annual growth and solar activity.

\section{Changes of cosmic ray intensity from 1744 to 1884}

In order to study cosmic rays time dependence in the past by investigating the concentration of cosmogenic isotopes in samples of known age, it is, undoubtedly, important to note the subject to an anthropogenic factor. The period from 1744 to 1884 is being investigated by yearly intervals. The results of the ${ }^{14} \mathrm{C}$ content measurements have been approximated by the sums of several most appropriate harmonic functions (Kocharov and others, 1977). Comparison of these results with Wolf's numbers shows a clearly negative correlation between ${ }^{14} \mathrm{C}$ content in the earth's atmosphere and solar activity. The following periods are established in the ${ }^{14} \mathrm{C}$ data: approximately 67 years with an amplitude of 0.46 percent, $T \approx 12$ years with an amplitude of 0.33 percent, and $T \approx 20$ years with an amplitude of 0.28 percent.

Total ${ }^{14} \mathrm{C}$ production rate in the earth's atmosphere at level $\mathrm{h}$ represents the variations of geomagnetic, atmospheric and extraterrestrial 
origin. Each of these components is characterized by the varying durations, type of influence and thus, by the various amplitudes in the ${ }^{14} \mathrm{C}$ content.

If the time interval is small, the ${ }^{14} \mathrm{C}$ content change in the earth's atmosphere may be considered as a result of solar activity. In such case, the ${ }^{14} \mathrm{C}$ production rate, at the moment $\mathrm{t}$, is

$$
\frac{\delta \mathrm{Q}\left(\mathrm{h}_{\mathrm{o}}, \mathrm{t}\right)}{\mathrm{Q}\left(\mathrm{h}_{\mathrm{o}}, \mathrm{O}\right)}=\int_{0}^{\infty} \frac{\delta \mathrm{D}(\mathrm{R}, \mathrm{t})}{\mathrm{D}(\mathrm{R}, \mathrm{O})} \mathrm{W}_{\mathrm{p}}\left(\mathrm{R}, \mathrm{h}_{\mathrm{o}}\right) \mathrm{dR}
$$

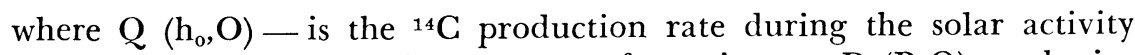
minimum; $D(R, t)$ - is the spectrum of cosmic rays; $D(R, O)$ - the interstellar cosmic ray spectrum; $\mathrm{R}$ - the rigidity; $W_{\mathrm{p}}\left(\mathrm{R}, \mathrm{h}_{\mathrm{o}}\right)$ - the planetary relationship coefficient of the ${ }^{14} \mathrm{C}$ production rate by cosmic rays (Dorman, 1978). Consequently, it is necessary to search for $\delta \mathrm{D}(\mathrm{R}, \mathrm{t}) / \mathrm{D}$ $(\mathrm{R}, \mathrm{O})$ from the value $\delta \mathrm{Q}\left(\mathrm{h}_{0}, \mathrm{t}\right) / \mathrm{Q}\left(\mathrm{h}_{\mathrm{o}}, \mathrm{O}\right)$ which can be obtained from the experimental data of the ${ }^{14} \mathrm{C}$ content (Dergachev, Kocharov, and Tleugaliev, 1979).

In order to solve this problem, ${ }^{14} \mathrm{C}$ transfer in the natural exchange reservoir must be known. Using a six-reservoir model (stratosphere, troposphere, upper ocean, deep ocean, biosphere, and humus) we concluded that the ${ }^{14} \mathrm{C}$ content may change during the 11-year solar activity cycle, up to $\sim 0.7$ percent and during the secular cycle, up to $\sim 1.2$ percent. The amplitudes of various harmonics in ${ }^{14} \mathrm{C}$ production rate were evaluated, taking into account the obtained value of amplitude attention coefficient in ${ }^{14} \mathrm{C}$ production and phase shift. These amplitudes are equal to 2.3 percent for the 67-year harmonics, 9.2 percent for the 11-year harmonics, and 4.7 percent for the 22-year harmonics.

Calculated values of the ${ }^{14} \mathrm{C}$ production rate in the earth's atmosphere were recalculated to solar activity minimum to find cosmic ray intensity variations relative to this minimum. Results are shown in figure 1 .

Thus, it is possible to restore cosmic ray intensity of the past, using ${ }^{14} \mathrm{C}$ data in samples of known age.

\section{${ }_{14} \mathrm{CO}_{2}$ and ${ }^{14} \mathrm{CO}$ in radiocarbon models}

In order to investigate individual natural phenomena (solar activity, supernova explosions, etc) using the ${ }^{14} \mathrm{C}$ level in the earth's atmosphere, ${ }^{14} \mathrm{C}$ distribution in exchange reservoirs must be known. At present, the simulation of radiocarbon exchange processes is commonly accepted and widely used for the study of various natural processes. For slow processes (thousands or tens of thousands years' duration) the diffusion box description of such processes is sufficiently coordinated. In this case, the atmosphere and oceans are considered as a whole (Dergachev and Stupneva, 1975; Oeschger and others, 1975).

For the description of the ${ }^{14} \mathrm{C}$ content changes of only a few years' duration, reliable models are necessary. The amplitude-frequency characteristic of the selected system essentially depends upon the chosen description level (Dergachev and Ostryakov, 1979). 
While restoring cosmic ray intensity using available ${ }^{14} \mathrm{C}$ data, the effects of varying character and duration must be separated. The most interesting is the study of processes related to the influence on galactic cosmic radiation, $i e$, short-term processes.

Unfortunately, owing to anthropogenic influence on the ${ }^{14} \mathrm{C}$ level in the earth's atmosphere, the precise calculation of ${ }^{14} \mathrm{C}$ production rate change by both galactic and solar cosmic rays appears problematic, despite available extensive information on cosmic rays.

How can we trace natural ${ }^{14} \mathrm{C}$ variation at present? It is known that ${ }^{14} \mathrm{C}$ is first oxidized to ${ }^{14} \mathrm{CO}$ after its production, and then into ${ }^{14} \mathrm{CO}_{2}$. The mixture of ${ }^{14} \mathrm{CO}$ and ${ }^{14} \mathrm{CO}_{2}$ together with the stable compounds is included in chemical and physical processes in the earth's atmosphere. The calculated profiles of the ${ }^{14} \mathrm{CO}$ and ${ }^{14} \mathrm{CO}_{2}$ in the atmosphere are presented in figure 2 (Alekseev and others, 1979). Principal photochemical sources and descents of $\mathrm{CO}$ and $\mathrm{CO}_{2}$, sources and descents at the earth's level, and the transfer by turbulent diffusion are taken into account. It

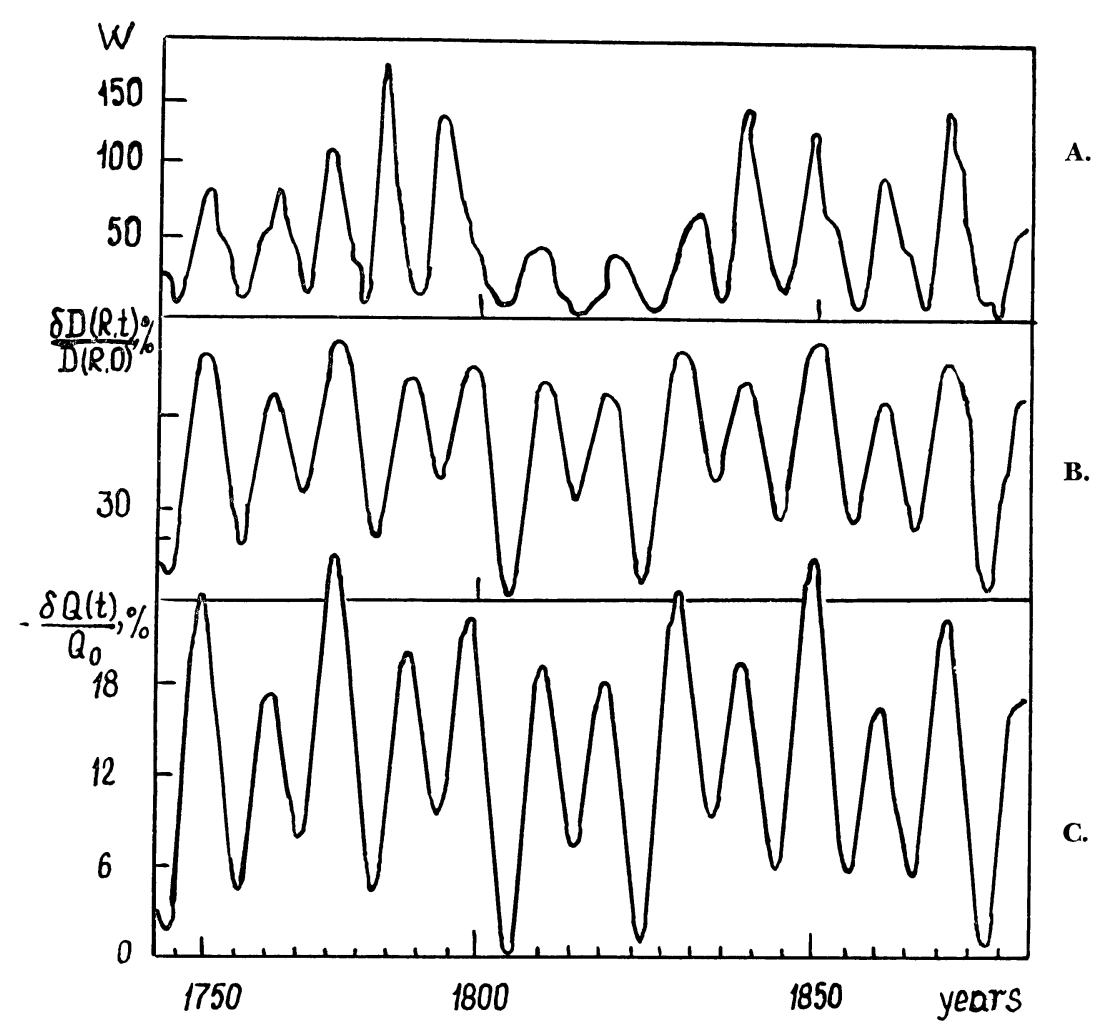

Fig 1. A) Sunspot number changes for the time interval, 1744 to 1884. B) Cosmic ray intensity variations $\left(\frac{\delta \mathrm{D}(\mathrm{R}, \mathrm{t})}{\mathrm{D}(\mathrm{R}, \mathrm{O})}\right)$ for the rigidity of $\sim 1 \mathrm{GV}$; C) ${ }^{14} \mathrm{C}$ production rate variations $\left(-\frac{\delta Q}{Q_{0}}\right)$ relative to solar activity minimum $Q_{0}$. 
is clear that the manifestation of solar activity is more pronounced in carbon monoxide. Comparison of profiles for the "cosmogenic" ${ }^{14} \mathrm{CO}$ $\left({ }^{14} \mathrm{CO}\right.$ set free in the atmosphere in various natural processes, including photochemical processes) show that at all altitudes, "cosmogenic" ${ }^{14} \mathrm{CO}$ content is considerably higher. "Biospheric" ${ }^{14} \mathrm{CO}_{2}$ content (taking into account the transfer of $\mathrm{CO}_{2}$ from atmosphere to biosphere and ocean and the return of $\mathrm{CO}_{2}$ to the atmosphere from the biosphere and ocean) is considerably higher in comparison with "cosmogenic" ${ }^{14} \mathrm{CO}_{2}$ content (at all altitudes for the $\mathrm{CO}_{2}$-cycle). This indicates that the cosmic source is manifested in "pure" sight in the ${ }^{14} \mathrm{CO}$ form, while in the ${ }^{14} \mathrm{CO}_{2}$ form, the cosmic source is smoothed considerably by carbon dioxide that permanently participates in exchange between the natural reservoirs of $\mathrm{CO}_{2}$.

Taking into account this fact and that $\mathrm{CO}$ and $\mathrm{CO}_{2}$ are fixed by plants in different conjunctions ( $\mathrm{CO}$ is fixed by plants apparently in the presence of protein, and $\mathrm{CO}_{2}$ in the presence of starch) (Bidwell and Fraser, 1972) it is hoped that ${ }^{14} \mathrm{CO}$ content in tree rings might be reconstructed for the past and that information will be gained about events in the past by studying CO contents in tree rings. This is an assumption only; thorough and detailed experimental verification is required. To solve these questions, regular ${ }^{14} \mathrm{CO}$ measurements in the atmosphere should be performed.

\section{The behavior of the solar magnetic field}

It is well known that the energy spectrum of the 11-year variations of galactic cosmic rays is associated with changes in solar activity. Moreover, certain features have been found in galactic flux variations that indicate a relationship between the calculated and experimental primary cosmic ray fluxes as a function of solar activity (Stozhkov and Charakhchyan, 1970). However, an unusual galactic cosmic ray flux enhancement in the heliosphere in 1970 to 1973 broke this relationship. A reversal of

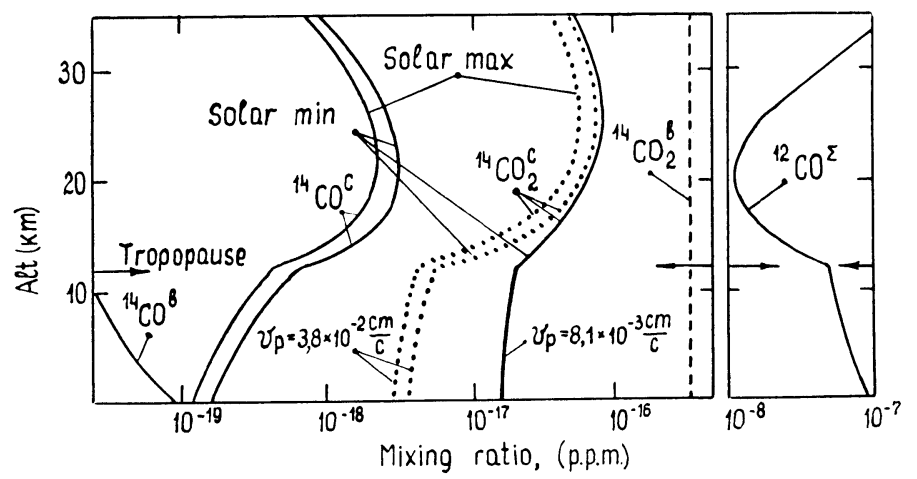

Fig 2. Radiocarbon and stable $\mathrm{CO}$ and $\mathrm{CO}_{2}$ content profiles in the earth's atmosphere $\left(\mathrm{CO}_{2}\right.$ velocity absorbed by the major ground-based sinks $\mathrm{v}=3.8 \cdot 10^{-2} \mathrm{~cm} / \mathrm{s} \mathrm{ob}$ tained on the assumption that $\mathrm{CO}_{2}$ velocity by the leaf of a plant is $9.5 \cdot 10^{-3} \mathrm{~g} \mathrm{CO}_{2} /$ hour $\mathrm{dm}^{2}$ of the leaf; piston velocity of $\mathrm{CO}_{2}$ in the ocean is $5.29 \cdot 10^{-3} \mathrm{~cm} / \mathrm{s}$. The velocity of $8.1 \cdot 10^{-3} \mathrm{~cm} / \mathrm{s}$ obtained on the assumption that the ocean output is $5 \mathrm{~mol} / \mathrm{m}^{2}$ year and the vegetable earth's bed-spread is $30 \mathrm{~mol} \mathrm{c} / \mathrm{m}^{2}$ year). 
the total solar magnetic field was probably the reason for this breakdown (Charakhchyan and others, 1973).

In the period of total solar magnetic field reversals, changes in heliomagnetospheric structure probably take place and can be reflected on cosmic ray flux coming into the solar system. Thus, the dual nature of the sun's modulating action on the galactic cosmic rays is possible. This duality manifests itself in sunspot activity and in total solar magnetic field changes. If the period of magnetic field changes is 22 years, this cyclicity must be pronounced in the time dependence of cosmic rays and also in ${ }^{14} \mathrm{C}$ activity level changes in the earth's atmosphere in the past. The influence of the total solar magnetic field on the ${ }^{14} \mathrm{C}$ production rate in the earth's atmosphere has been investigated by Dergachev and Malchenko (1979) for the different solar activity periods. Experimental data on the galactic cosmic ray spectra at the atmosphere boundary, the data on neutrons in the earth's atmosphere, and also the modulation coefficients for different levels of solar activity have been analyzed.

The results of the mean global ${ }^{14} \mathrm{C}$ production rate $\mathrm{Q}$ determination for the various solar activity levels from 1959 to 1972 are shown in figure 3. Comparison of the calculated ${ }^{14} \mathrm{C}$ production rates for normal and anomalous courses of the 11-year cycle shows that at the time of maximum manifestation of an anomaly in the galactic cosmic ray flux (1972) the rates differ by about $\sim 50$ percent.

Thus, if such anomalies took place in the past, their effects may be studied in the long series of high-precision ${ }^{14} \mathrm{C}$ determination taking into account the response function of the atmosphere.

\section{Irregular solar activity}

After the discovery of varying solar activity manifestations in cosmic rays in the 19th and 20th cycles of the 11-year solar activity, considerable interest in solar activity minima occurred. It appeared that the 20th cycle was more powerful than the 19th and it swept more strongly galactic

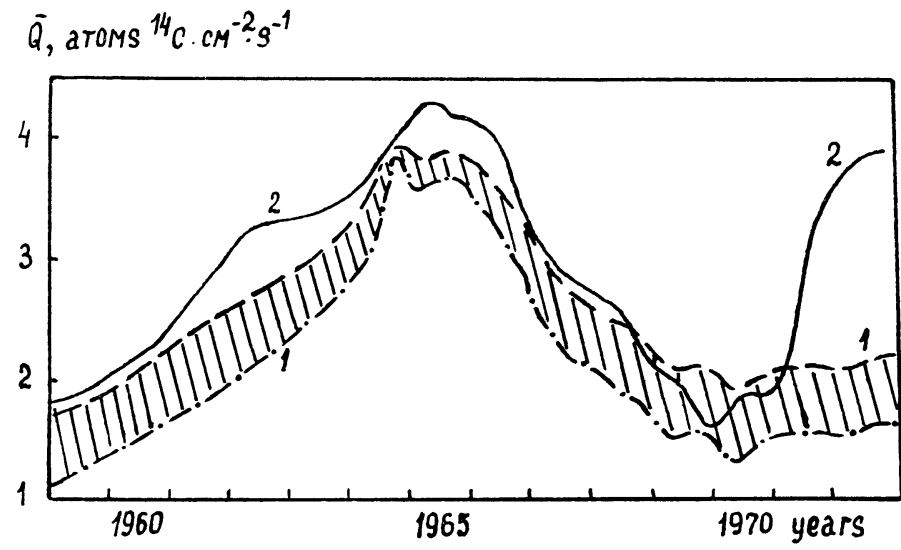

Fig 3. Mean global radiocarbon production rate versus variation of solar activity in the period, 1959 to 1972: 1) Normal course of 11-year cycle; 2) Anomalous course. 
cosmic rays from the solar system. The situation attracted attention to Maunder's (1645-1715) and Spörere's (1470-1550) minima. Forman, Schaeffer, and Schaeffer (1977) pointed out that cosmogenic isotopes increase in meteorite as well as in cosmogenic radiocarbon. Consequently, ${ }^{14} \mathrm{C}$ content changes are traced to the level of solar activity. Moreover, ${ }^{14} \mathrm{C}$ activity can be considered as a level of galactic cosmic ray modulation. Solar activity breakdown and corresponding anomalies in cosmic ray intensity are now widely investigated. There are a number of explanations for the sharp decrease in sunspot solar activity.

A satisfactory theory to explain the flare activity of the sun does not exist. One possibility is that the series of observational data on solar flares are too short. Unfortunately, neither solar flares nor sunspot numbers were recorded in the past. However, nature preserves information about solar flares, for example, in radiocarbon data, particularly during periods of increased solar activity. Anthropogenic influence of the ${ }^{14} \mathrm{C}$ level makes it difficult to investigate the flare activity of the sun in the "radiocarbon window" at present. If the experiments with ${ }^{14} \mathrm{CO}$ in the atmosphere and the biosphere, mentioned above will be conclusive for the study of ${ }^{14} \mathrm{C}$ content variations due to the cosmic reasons we can hope to decipher the problem of solar flares based on detailed study of ${ }^{14} \mathrm{C}$ concentration in the past. From this point of view, periods of extreme solar activity are very interesting.

We only know about the moment of some solar flares, recorded before atomic tests. What does radiocarbon data show about these flares?

Figure 4 shows results of ${ }^{14} \mathrm{C}$ level determination in various samples for the period from 1932 to 1952 (Damon, Long, and Wallick, 1973;

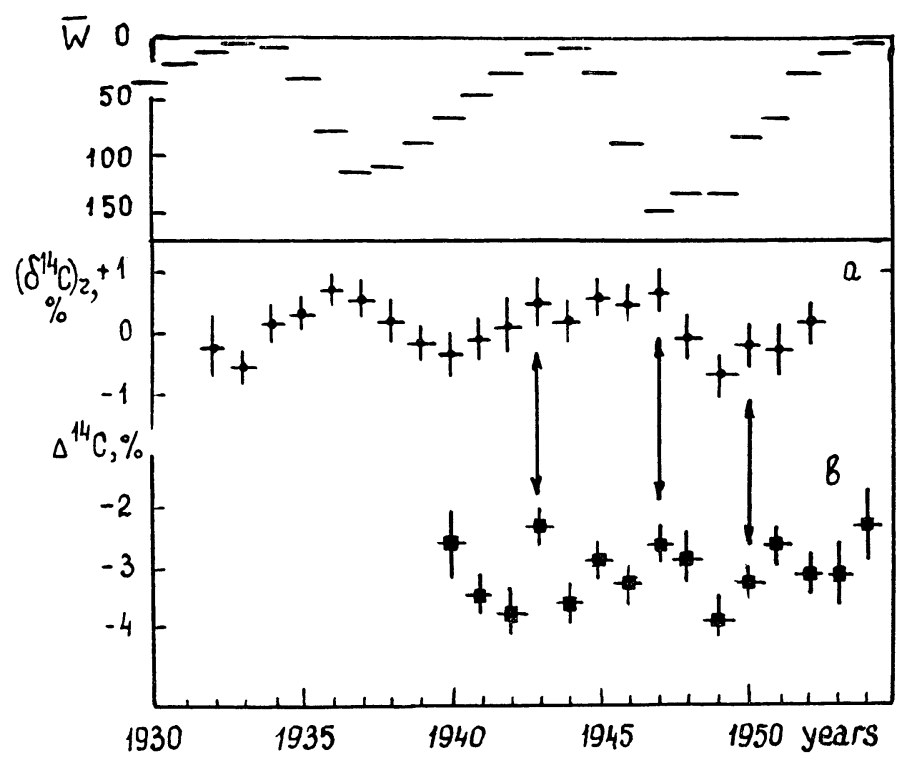

Fig $4 .{ }^{14} \mathrm{C}$ content changes and solar activity of the period, 1932 to 1954 , according to a) Wergachev and Povinec (1978); B) Damon, Long, and Wallick (1973). 
Dergachev and Povinec, 1978). No data is available for the flare of 1937. The flares of 1942 and 1946, which were weak, took place during decreased solar activity; the flares of 1937 and 1949 took place in the solar activity maximum which could make a definite contribution to ${ }^{14} \mathrm{C}$ production. In spite of considerable errors, the ${ }^{14} \mathrm{C}$ content increased the year after the flares (arrows in fig 4). Of course, it is still impossible to draw definite conclusions about the phenomena observed, and separate and detailed studies of the effects of galactic cosmic rays, solar activity (cyclic and flared) and solar cosmic rays for long intervals are necessary.

\section{REFERENCES}

Alekseev, V B and Dergachev, V A, 1978, On the carbon oxide cycle incorporated in the model of cosmogenic radiocarbon transfer: Leningrad, Physico-Technical Inst, Preprint (in Russion), no. 597.

Alekseev, V B, Dergachev, V A, Karol, I L, and Kocharov, G E, 1979, Transfer model of cosmogenic radiocarbon taking into account the carbon oxide cycle: Leningrad, Physico-Technical Inst, Preprint (in Russian), no. 627.

Bidwell, R G S and Fraser, D E, 1972, Carbon monoxide uptake and metabolism by leaves: Canadian Jour Botany, v 50, p 1435-1439.

Bitvinskas, T, Daukantas, A, Dergachev, V, Liiva, A, Suurman, S, and Shulia, K, 1978, Using the radiocarbon method to create extra long-term dendroscales, in Bitvinskas, $T$ T, ed, Environmental condition and radial increment of trees (in Russian):
Kaunas, p 51-55.

Charakhchyan, A N, Krainev, M B, Svirzhevskaya, A K, Stozhkov, Yu I, and Charakhchyan, $T$ N, 1973, Anomalous effect in the 11-year galactic cosmic ray modulation, in Internatl cosmic ray conf, 13th, Proc: Denver, Colo, v 2, p 1159-1164.

Damon, P E, Long, Austin, and Wallick, E I, 1973, On the magnitude of the 11-year radiocarbon cycle: Earth Planetary Sci Letters, v 20, p 300-306.

Dergachev, V A and Kocharov, G E, 1980, Natural processes and time fluctuations in the radiocarbon concentration of the atmosphere, in Stuiver, Minze and Kra, Renee, eds, Internatl radiocarbon conf, 10th, Proc: Radiocarbon, v 22, no. 2, p 236-244.

Dergachev, V A, Kocharov, G E, and Stupneva, A V, 1978, Cyclicity of the pine wood growth with solar activity, in Bitvinskas, T T, ed, Environmental condition and radial increment of trees (in Russian): Kaunas, $p$ 72-74.

Dergachev, V A, Kocharov, G E, and Tleugaliev, S Kh, 1979, Changes of cosmic ray intensity in the past: Leningrad, Physico-Technical Inst, Preprint (in Russian), no. 620 .

Dergachev, V A and Malchenko, N I, 1979, On the possibility of the study of the total solar magnetic field behavior in the past, in Internatl cosmic ray conf, 16th, Kyoto, Japan, Proc: SP 6-1.

Dergachev, V A and Ostryakov, V M, 1979, On the diffusive distribution of cosmogenic radiocarbon in the dynamic reservoir: Acad Sci USSR Bull, Physics ser, v 43, no. 4.

Dergachev, V A and Povinec, P, 1978, 11-year solar activity cycle and radiocarbon content variations, in Kocharov, G E, Dergachev, V A, Mirianashvili, G M, and Sanadze, A A, ed, All-Union conf on astrophysical phenomena and radiocarbon, 6th, Proc, 1976, (in Russian): Tbilisi Univ Press, p 37-48.

Dergachev, V A and Stupneva, A V, 1975, Some problems on choice of optimal carbon dynamic reservoir model: Leningrad, Physico-Technical Inst, Preprint (in Russian), no. 491 .

Dorman, L I, 1978, Peculiarities of cosmic ray variation studies by means of radio. carbon technique, in Kocharov, G E, Dergachev, V A, Mirianashvivli, G M, and Sanadze, A A, eds, All-Union conf on astrophysical phenomena and radiocarbon 6th, Proc, 1976 (in Russian): Tbilisi Univ Press, p 40.

Fergusson, C W, 1972, Dendrochronology of the bristle cone pine, in Rafter, $\mathrm{T} A$ and Grant-Taylor, $T$, eds, Internatl radiocarbon dating conf, 7 th, Proc: Wellington, New Zealand, Royal Soc New Zealand, p 117.

Forman, M A, Schaeffer, O A, and Schaeffer, G A, 1977, Meteoric evidence for the Maunder Minimum in solar activity, in Internatl cosmic ray conf, 15 th, Plovdiv, Proc: v 3, p 187-192. 
Kocharov, G E, Arslanov, KhA, Dergachev, V A, Tleugaliev, S Kh and Chernov, S B, 1977, Cyclic activity of the sun and radiocarbon content in tree-rings: Astron Jour Letters, v 3, p 474-476.

Kolchin, B A, 1972, Dendrochronology of Novgorod, in Problems of the absolute dating in archaeology (in Russian): Moscow, Nauka.

Lin, Y C, Fan, C Y, Damon, P E, and Wallick, E J, 1975, Long term modulation of cosmic ray intensity and solar activity cycle, in Internatl cosmic ray conf, 14th, Munich, Proc: v 3, p 995-999.

Oeschger, Hans, Siegenthaler, Ulrich, Schotterer, Ulrich, and Gugelmann, A, 1975, A box diffusion model to study the carbon dioxide exchange in nature: Tellus, v 27 , p 168-192.

Stozhkov, Yu I, and Charakhchyan, T N, 1970, Changes of the energetic spectrum of galactic cosmic rays during the 11-year solar activity cycle: Acad Sci USSR Bull, Physics ser, v 34, no. 12. 